\title{
Aspirin and Cardiovascular Primary Prevention in Non-Endstage Chronic Kidney Disease: A Meta-Analysis
}

\author{
Rupert W Major ${ }^{1,2}$ \\ Issaam Oozeerally ${ }^{2}$ \\ Simon Dawson ${ }^{2}$ \\ Helen Riddleston ${ }^{2}$ \\ Laura J Gray ${ }^{1}$ \\ Nigel J Brunskill ${ }^{2,3}$
}

\section{Affiliations}

1. Department of Health Sciences, University of Leicester, UK

2. John Walls Renal Unit, University Hospitals of Leicester, UK

3. Department of Infection, Immunity and Inflammation, University of Leicester, UK

\section{Keywords}

1. aspirin

2. cardiovascular disease

3. chronic kidney disease

4. primary prevention

Tables: 2, Figures: 3

Word count:

\section{Corresponding Author}

Dr Rupert W Major

Department of Health Sciences, University of Leicester

University Road, Leicester, LE1 7RH, UK

Email: rwlm2@le.ac.uk 


\section{Abstract}

\section{Background and Aims}

Chronic kidney disease is a strong independent predictor of cardiovascular disease. No published meta-analyses of the use of aspirin for the primary prevention of cardiovascular disease in chronic kidney disease exist. We therefore performed a systematic review and meta-analysis of this subject.

\section{Methods}

We used a pre-defined and registered protocol (PROSPERO identification CRD42014008860). We searched Medline and Embase between 1996 and July 2015. Inclusion criteria were adult subjects with non-endstage chronic kidney disease (CKD) and no history of cardiovascular disease. The co-primary outcomes were major cardiovascular events and all-cause mortality. Secondary outcomes included bleeding-related events. We used a random effects model to pool data.

\section{Results}

Three trials were identified and two of these provided previously unpublished data. The studies included 4,468 participants and 16,740 person-years of follow-up. There were no statistically significant reductions in the risk of major cardiovascular events (RR $0.92,95 \% \mathrm{Cl} 0.49$ to $1.73, p=0.79, \mathrm{I}^{2} 71 \%$ ) or mortality (RR $0.74,95 \% \mathrm{Cl} 0.55$ to $1.00, p=0.05,1^{2} 0 \%$ ) with aspirin compared to the control group. Major bleeding events were increased with aspirin though (RR 1.98, 95\% $\mathrm{Cl} 1.11$ to $3.52, p=0.02, \mathrm{I}^{2}$ $0 \%)$.

\section{Conclusions}

There is no clear benefit of aspirin for the primary prevention of cardiovascular events in CKD and no statistically significant reduction in mortality. Aspirin is likely to increase the risk of major bleeding events. Currently, insufficient randomised control trial data exists to recommend universal use or avoidance of aspirin for primary 
prevention of cardiovascular events in CKD. 


\section{Introduction}

Chronic kidney disease (CKD) affects approximately $6-8 \%$ of the adult population [1]. It is an independent risk factor for atherosclerotic disease [2]. Aspirin irreversibly inhibits the production of thromboxane and hence prevents platelet aggregation. Its role is well established in the secondary prevention of cardiovascular disease (CVD) [3] and to a lesser degree in high risk groups for primary prevention, such as those with diabetes mellitus $[4,5]$. However, aspirin is associated with increased risk of bleeding, with gastrointestinal and cerebral haemorrhage contributing to morbidity and mortality [6].

Aspirin's role in the primary prevention of CVD in CKD has been identified as an important research priority $[7,8]$. However, only one relevant trial is presently registered with clinicaltrials.gov [9]. Whilst its efficacy may be higher in the prevention of CVD events [10], there is also a potentially greater risk of bleeding in CKD [11]. Previous meta-analyses have only considered the broader category of 'anti-platelets' and have included individuals with end-stage renal failure and established CVD [12].

Currently, aspirin use is recommended in national and international guidance in CKD for secondary prevention, but not primary prevention of CVD events $[7,8]$. European guidance specifically for diabetic CKD recommends that aspirin only be commenced for primary prevention in the absence of major bleeding risk factors [13].

In the general population, the Antithrombotic Trialists' (ATT) Collaboration [6] has provided perhaps the most comprehensive data in relation to CVD primary prevention with aspirin. Aspirin produced a $12 \%$ relative risk reduction in CVD events. However, in absolute terms this equated to a $0.06 \%$ per annum reduction in CVD events. Haemorrhagic strokes were increased by $32 \%$, or $0.01 \%$ each year. Major extracranial bleeds showed a similar pattern with a $54 \%$ and $0.03 \%$ increase respectively. This reinforces the importance of event rates when trying to balance the risk and benefits in a primary prevention programme. CVD and bleeding prognostic models have not been validated in CKD. Since both the risk and potential benefit 
varies as estimated glomerular filtration rate (eGFR) changes [10], making an accurate assessment becomes problematic.

This systematic review and meta-analysis aimed to assess the role of aspirin for the primary prevention of CVD in CKD patients. 


\section{Subjects and Methods}

We used a pre-defined and registered systematic review and meta-analysis protocol (PROSPERO identification CRD42014008860) [14]. We searched OVID Medline and Embase between 1996 and July 2015 using no language restrictions (see appendix 1 for full search strategy for OVID Medline). In addition, the National Institute of Health Research database of clinical trials and Cochrane databases were also searched. Other related reviews were also assessed for additional trials.

The inclusion criteria were randomised controlled trials in adult participants with any stage of non-endstage CKD and no history of CVD. Exclusion criteria were head-tohead studies of aspirin versus other anti-platelet medications, studies in primary renal disease (eg IgA nephropathy, vasculitis), or any trial with more than $5 \%$ of participants with a history of CVD.

The co-primary outcomes were major CVD events and all-cause mortality. Secondary outcomes included coronary heart disease events, stroke and major or minor bleeding-related adverse events. Major bleeding events were defined as any bleeding event leading to hospitalisation or death. Minor bleeding events encompassed any other bleeding event reported in the trial. All identified abstracts were independently assessed by two authors. Each reviewer shortlisted potential studies for further consideration. The full text of all identified papers was then reviewed independently by another two authors.

The quality of the studies' methodology, including bias and identification of CKD subgroups, were then assessed individually. All studies were assessed unblinded using a standardised proforma based on the Cochrane Handbook [15]. Assessments from the reviewers were compared and any differences were discussed until a consensus was achieved.

Outcome data were extracted using a predefined template by one reviewer and cross-checked to the original publication by another reviewer. Corresponding authors were contacted for additional unpublished data. Data were analysed using RevMan 5.2. Random effects model using Mantel-Haenszel (M-H) method were 
used to pool the data. A random effects model was chosen as heterogeneity was expected to be high. Relative and absolute pooled risk reductions were calculated as well as the number need to treat/harm over five years of treatment. Subgroup analyses were planned if heterogeneity was greater than $I^{2}>25 \%$ and included CKD stage, estimated glomerular filtration rate formula used, follow-up length ( $<2$ years, $>2$ years) and the trials' proportion of diabetes mellitus and hypertension. 


\section{Results}

One thousand three hundred and fourteen abstracts were reviewed. Figure 1 shows the screening process including the number of studies identified and excluded.

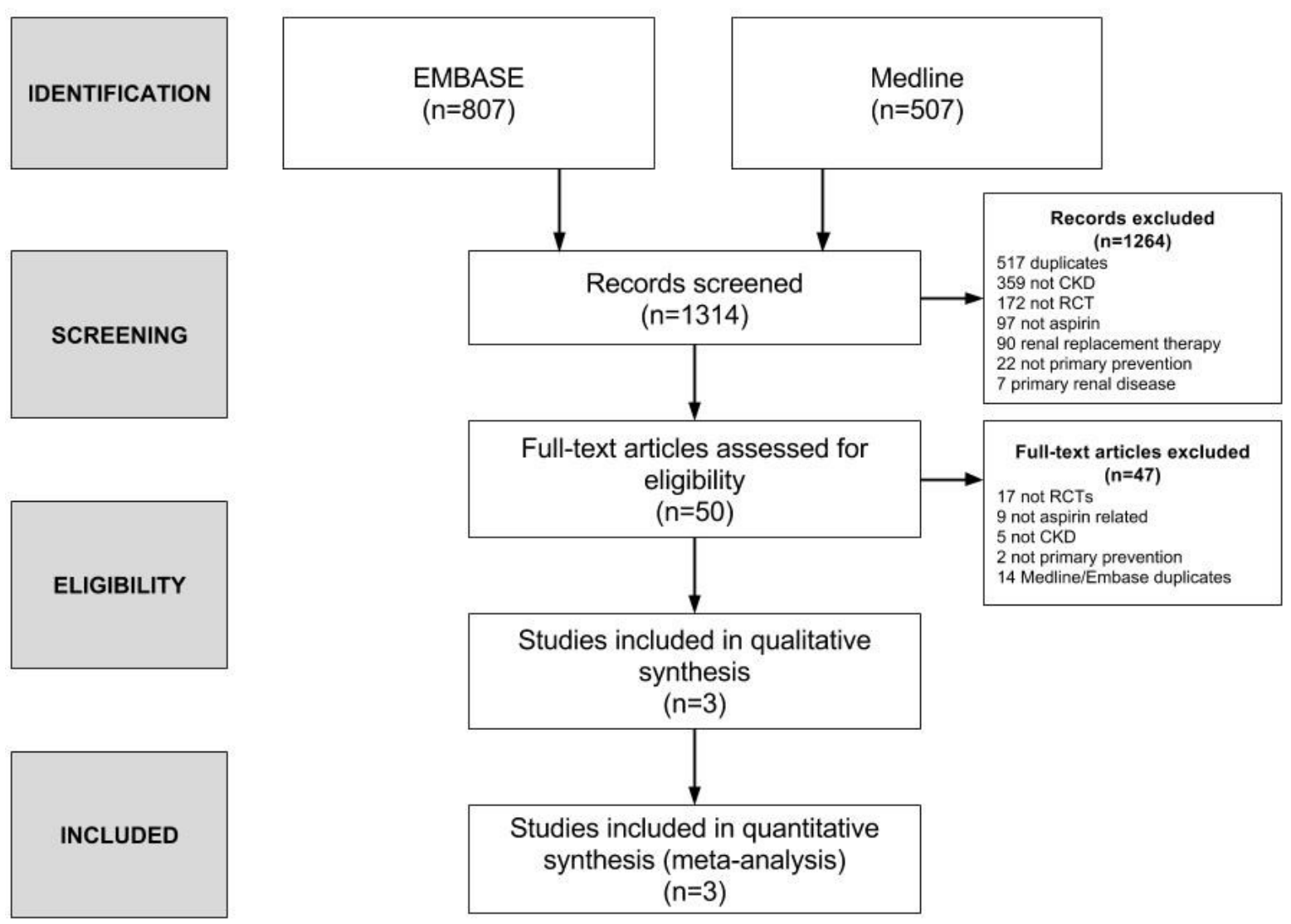

Figure 1: Flowchart showing the number of papers identified, screened and included in the metaanalysis

The search identified three trials, and their key characteristics are described in table $1[10,16,17]$. These trials included a total of 4,469 individuals with CKD. All trial results were published in peer-review journals. Additional data were supplied by the authors of HARP and JPAD $[16,17]$. 


\begin{tabular}{|c|c|c|c|c|c|c|c|c|c|c|c|c|}
\hline Study & $\begin{array}{l}\text { Aspirin } \\
\text { Dose }\end{array}$ & Control & $\begin{array}{l}\text { Number of } \\
\text { Participants } \\
\text { in Main } \\
\text { Cohort }\end{array}$ & $\begin{array}{l}\text { Number of } \\
\text { Participants } \\
\text { with non- } \\
\text { endstage CKD }\end{array}$ & $\begin{array}{l}\text { Primary } \\
\text { Outcome }\end{array}$ & $\begin{array}{l}\text { Diabetes } \\
\text { Mellitus }\end{array}$ & Hypertension & $\begin{array}{l}\text { Mean/Median } \\
\text { Follow-up in } \\
\text { Months }\end{array}$ & $\begin{array}{l}\text { Mean Age of } \\
\text { Participants } \\
\text { in Years }\end{array}$ & $\begin{array}{c}\text { CKD } \\
\text { Definition }\end{array}$ & $\begin{array}{l}\text { eGFR } \\
\text { Formula }\end{array}$ & $\begin{array}{l}\text { Mean (SD) } \\
\text { eGFR/SCr of } \\
\text { CKD Cohort }\end{array}$ \\
\hline $\begin{array}{l}\text { HARP } \\
(2005) \\
(16)\end{array}$ & $100 \mathrm{mg}$ & $\begin{array}{l}\text { Placebo (2x2 } \\
\text { design with } \\
\text { simvastatin) }\end{array}$ & 448 & $\begin{array}{l}218 \\
\text { (remaining } \\
\text { ESRF or Hx } \\
\text { CVD) }\end{array}$ & Not specified & $6.9 \%$ & Not available ${ }^{*}$ & 12 & $\begin{array}{l}53 \text { (whole } \\
\text { cohort) }\end{array}$ & $\begin{array}{l}\text { original } \\
\text { paper - } \\
\text { serum } \\
\text { creatinine } \\
\text { level } \geq 1.7 \\
\mathrm{mg} / \mathrm{dL}[\geq 150 \\
\mu \mathrm{mol} / \mathrm{L}]\end{array}$ & MDRD & $\begin{array}{l}\text { Aspirin - } 28.3 \\
\text { (13.8), } \\
\text { Placebo } 30.8 \\
\text { (13.5) }\end{array}$ \\
\hline $\begin{array}{l}\text { HOT } \\
\text { (2010) } \\
(10)\end{array}$ & $75 \mathrm{mg}$ & Placebo & 18,597 & 3,619 & $\begin{array}{l}\text { Cardiovascular } \\
\text { Events }\end{array}$ & $8.6 \%$ & $100 \%$ & $\begin{array}{l}45.6 \text { (whole } \\
\text { cohort) }\end{array}$ & 65 & $\begin{array}{l}\text { eGFR<60 } \\
\mathrm{ml} / \mathrm{min} / 1.73 \\
\mathrm{~m} 2\end{array}$ & MDRD & 52.7 \\
\hline $\begin{array}{l}\text { JPAD } \\
\text { (2011) } \\
(17)\end{array}$ & $\begin{array}{l}81 \mathrm{mg} \text { or } \\
100 \mathrm{mg} \\
\text { (physician } \\
\text { discretion) }\end{array}$ & Nothing & 2,523 & 632 & $\begin{array}{l}\text { Atherosclerotic } \\
\text { Events }\end{array}$ & $100 \%$ & $69.6 \%$ & 52.4 & $68(8)$ & $\begin{array}{l}\text { eGFR<60 } \\
\mathrm{ml} / \mathrm{min} / 1.73 \\
\mathrm{~m} 2\end{array}$ & $\begin{array}{l}\text { three-variable } \\
\text { Japanese } \\
\text { equation for } \\
\text { GFR }\end{array}$ & $\begin{array}{l}\text { Serum } \\
\text { creatinine } 1.1 \\
\mathrm{mg} / \mathrm{dL} \text { (SD } \\
0.4 \text { ) }\end{array}$ \\
\hline
\end{tabular}

Table 1: Summary details of included studies. Study acronyms - HARP - 'First United Kingdom Heart and Renal Protection', HOT - 'Hypertension Optimal Treatment', JPAD - 'The Japanese Primary Prevention of Atherosclerosis With Aspirin for Diabetes'. Data from HARP for the percentage of individuals with hypertension in the CKD subgroups was not available, in the whole HARP cohort mean systolic blood pressure was $144 \mathrm{mmHg}(\mathrm{SD} 20 \mathrm{mmHg})$ in the aspirin group and $142 \mathrm{mmHg}$ (SD $21 \mathrm{mmHg}$ ) in the placebo group. Mean diastolic blood pressure was $83 \mathrm{mmHg}$ (SD $12 \mathrm{mmHg}$ ) in the aspirin group and $84 \mathrm{mmHg}$ (SD $11 \mathrm{mmHg}$ ) in the placebo group. 
The assessment of the trials' quality showed medium to high levels of bias, mainly related to the suboptimal identification of CKD and assessment of endpoints in the trials. The full results of the bias assessment are available in appendix 2. Two trials reported estimated glomerular filtration rate (eGFR) based on the Modification of Diet in Renal Disease (MDRD) equation [18]. The other trial used a Japanese-specific eGFR formula [19]. HARP was the only CKD-specific trial. The other two trials did not pre-specify a CKD subanalysis and both used one serum creatinine for the diagnosis of CKD. JPAD was an exclusively DM related study, whereas the other two trials had less than $10 \%$ of their population with DM. JPAD was also deemed to be at high risk of bias due to its open-label nature of group allocation.

Table 2 summarises the overall results of the random effects models for the pooled risk ratios, absolute risk reductions and numbers needed to treat over five years. All three trials reported data relating to major CVD events, but one trial did not report any events in either the intervention or control arms. Overall, 225 events occurred in 4,469 individuals $(5.0 \%)$ over a total of 16,740 person-years. There was no statistically significant reduction in the risk of major CVD events with aspirin compared to placebo (Risk Ratio (RR) 0.92, 95\% confidence interval (Cl) 0.49-1.73), $p=0.79)$ and there was a high level of heterogeneity $\left(I^{2}=71 \%, p=0.06\right)$. Figure 2 shows the forest plot for major CVD events. 


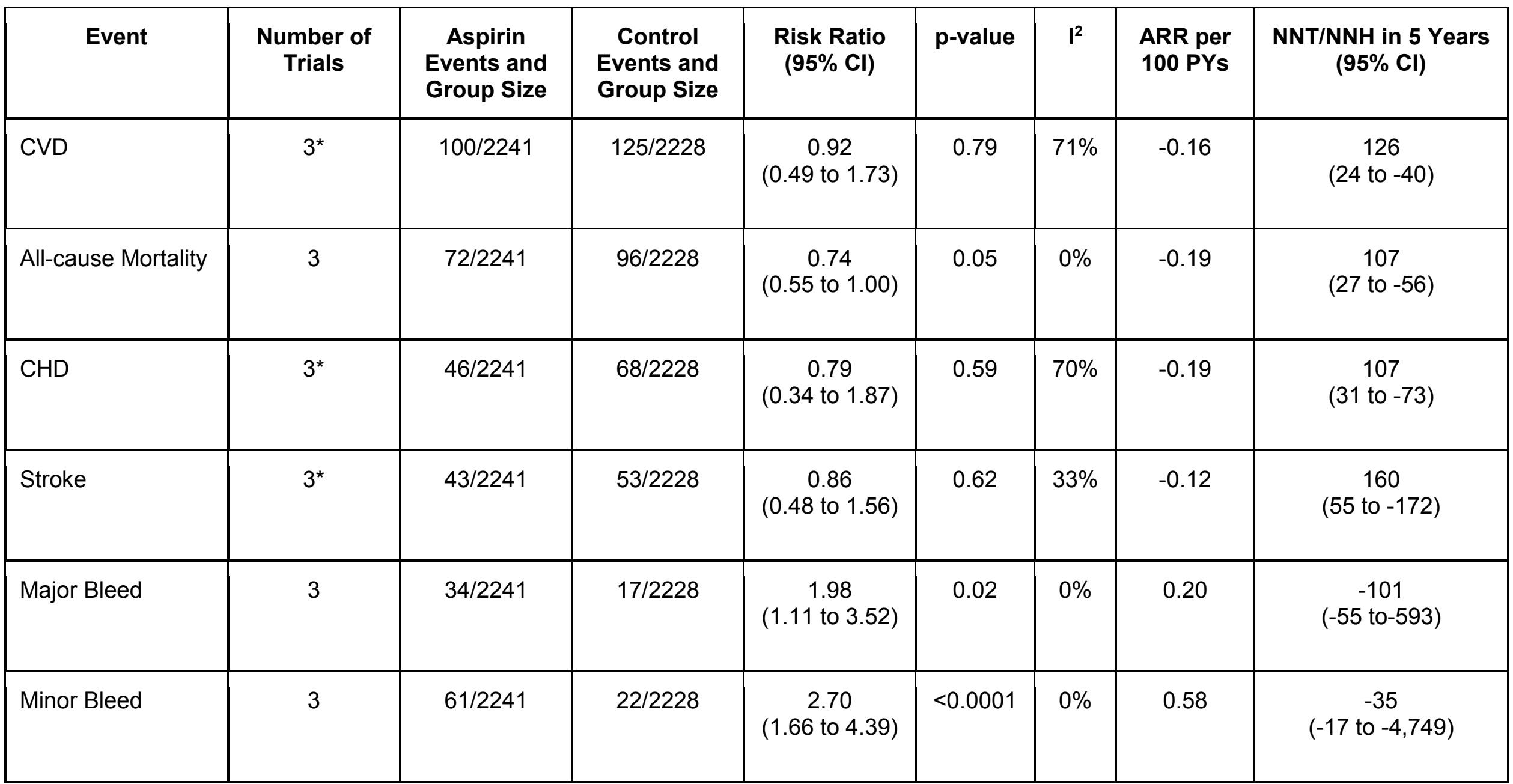

Table 2: Summary results by event type including random effects models, heterogeneity $\left(I^{2}\right)$, ARR per 100 person-years and NNT over 5 years to prevent one event. *The HARP study did not have any CVD, CHD or stroke events in the aspirin or placebo groups. 


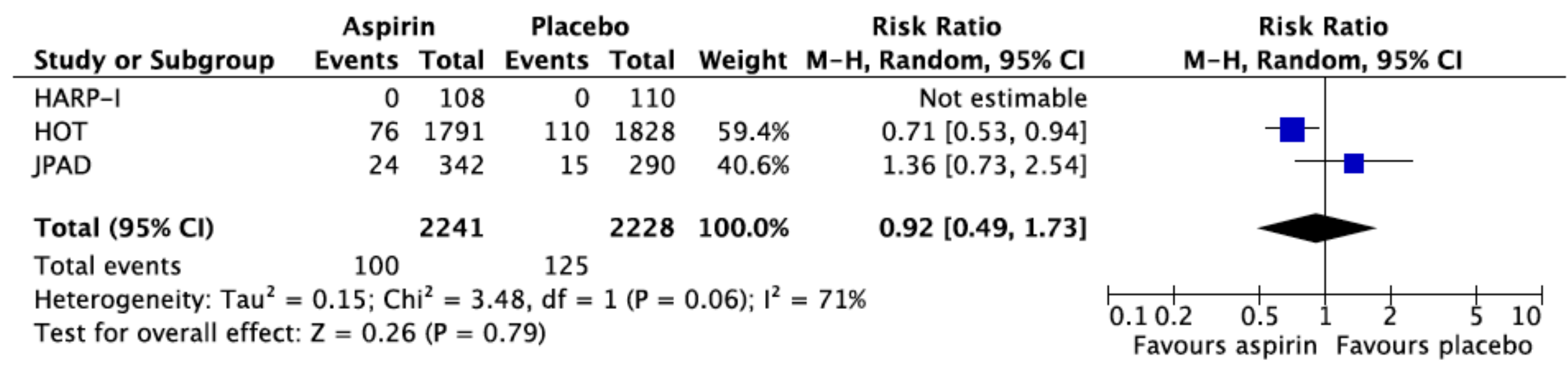

Figure 2: Forest plot of risk ratios for CVD events using a random effects model and $\mathrm{M}-\mathrm{H}$ method. 
All three trials reported all-cause mortality data. 168 events occurred in 4,469 individuals $(3.8 \%)$ over a total of 16,740 person-years. There was no statistically significant reduction in mortality with aspirin use compared to placebo ( $R R$ 0.73, 95\% $\mathrm{Cl} 0.54-1.00, p=0.05)$ there was a low level heterogeneity $\left(\mathrm{I}^{2}=0 \%, p=0.38\right)$.

Bleeding events were reported by all three trials and were separated into 'minor' and 'major' events. Major adverse events generally related to hospitalisation or death due to either gastrointestinal or cerebral haemorrhage. Over a total of 16,740 person-years follow-up 51 major bleed events occurred in 4,469 individuals (1.1\%). There was almost a doubling of major bleeding events with aspirin compared to placebo (RR 1.98, 95\% Cl 1.11-3.52, $p=0.02)$. There was a low level of heterogeneity $\left(I^{2} 0 \%, p=0.97\right)$. The forest plot for major bleeding events is shown in Figure 3. 


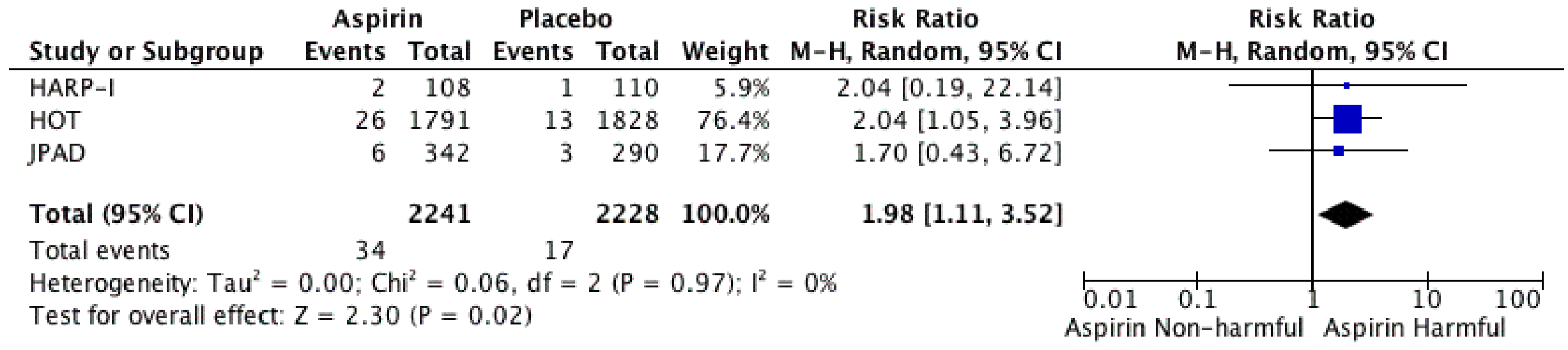

Figure 3: Forest plot of risk ratios for major bleeding events using a random effects model and $\mathrm{M}-\mathrm{H}$ method. 
Only the HARP trial provided data in relation to renal related outcomes. There was no significant difference between the aspirin and placebo groups for any predetermined outcome. Minor adverse events were less precisely defined but again related to bleeding events such as bruising. Again, there was a statistically significant increase in minor bleeding events with aspirin (RR 2.70, 95\% Cl 1.66$4.39, p<0.0001)$ and heterogeneity was low $\left(I^{2} 0 \%, p=0.47\right)$. Subgroup analysis was not performed due to the small number of trials in the analysis. 


\section{Conclusions}

Previous meta-analyses have suggested that anti-platelet therapy, including but not exclusive to aspirin, lowers the risk of CVD events across a range of CKD including individuals receiving maintenance dialysis [12]. These analyses also included individuals with previous CVD events and those without. The current meta-analysis addressed the specific questions of whether aspirin for the primary prevention of CVD events in non-endstage CKD was effective, and whether it was associated with increased bleeding. Aspirin in this group of patients is an attractive potential primary prevention therapy because CVD risk is excessive compared to non-CKD individuals. However, caution has been given due to the higher risk of haemorrhage due to uraemia related platelet dysfunction [20]. It is suggested that aspirin-induced thromboxane inhibition-mediated impairment of platelet aggregation, combined with uraemia could lead to excess bleeding events.

The pre-specified primary outcomes for the meta-analysis of CVD events and allcause mortality did not show a statistically significant reduction in events. However, the 'non-significant' p-value for all-cause mortality was 0.05 and had there been one less death in the aspirin group then the p-value would have been $<0.05$ and therefore 'significant'. We therefore suggest that this result should be interpreted with caution. What is more clearly suggested by the data is that there is increased risk of both major and minor bleeding events with aspirin.

The lack of a conclusive trial, or trials, in relation to this fundamental questions of CVD risk management in CKD is clearly disappointing. Further, at present only one trial in relation to this topic [9] is registered with a prospective clinical trials registry. The only CKD specific trial in this analysis, HARP [16], was not powered to assess 'hard' endpoints such as CVD events or mortality. The other two trials included in this meta-analysis were both post-hoc subanalyses of general population trials $[10,17]$.

Currently in the general population, meta-analyses suggest the CVD risk reduction of aspirin outweighs the bleeding risk in some groups [6,21]. This is based on accurate CVD risk prediction tools and full assessment of the associated haemorrhage. 
Within CKD, the former risk tools have not been validated [22, 23] and the increased bleeding risk is not quantifiable based on current data.

Taken as a whole, the current data suggests that treating one hundred individuals with CKD for five years with aspirin would lead to one additional death or hospitalisation due to major haemorrhage without any definite CVD benefit. There were insufficient data to perform the pre-specified subgroup analysis, including no usable data in relation to the impact of aspirin on the progression of renal disease.

The assessment of bias for the trials in question suggested that there was a medium to high risk of bias across all trials. The risk of bias in HOT [10] and JPAD [17] was increased by their subgroup analysis nature. Neither trial pre-specified a CKD subgroup analysis, and both relied on the suboptimal method of a single serum creatinine to diagnose CKD. Further, the multi-factorial designs of both HARP [16] and HOT [10] may introduce potential bias between the intervention groups. HARP was a 2x2 design with simvastatin as the second intervention. In addition to aspirin, the HOT studied diastolic blood pressure targets in a $2 \times 3$ design. However there was no evidence of a difference between group characteristics within either of these studies and therefore the minimising the risk of bias. A form of subgroup publication bias may exist within this area because there are a number of large general population aspirin primary prevention trials that have not at present published CKD subgroup analysis $[6,21]$. This may relate to a lack of recorded renal function data at trial commencement.

There was limited heterogeneity between the different trials for some outcomes. This may reflect the small number of trials included. In addition, the trials' population characteristics varied with the most notable feature being the baseline mean eGFR. HARP's mean eGFR was $29 \mathrm{ml} / \mathrm{min} / 1.73 \mathrm{~m}^{2}$ compared to more than 50 $\mathrm{ml} / \mathrm{min} / 1.73 \mathrm{~m}^{2}$ for the other two trials. The prevalence of diabetes mellitus and hypertension varied between the included trials. JPAD was exclusively a DM trial and HOT a hypertension trial. Whilst the heterogeneity of these co-morbidities may potentially limit the findings of this meta-analysis, CKD remains a potent CV risk factor regardless of the presence or absence of DM or hypertension. This has been confirmed in large individual patient level meta-analyses in CKD compared to non- 
CKD individuals for both all-cause and cardiovascular mortality and morbidity $[24,25,26]$.

The findings of increased risk of adverse events was consistent across all three studies regardless of the different trials' characteristics as potential sources of heterogeneity. Whilst subgroup analysis based on a number of variables was planned in the pre-specified methods this was not performed as the small number of trials meant that the subgroup results were unlikely to provide meaningful conclusions.

Previously published evidence in relation to the topic of this meta-analysis was largely from observational studies. Kim et al performed a retrospective analysis of 1884 individuals receiving aspirin matched to 1884 not receiving aspirin [11]. Approximately two thirds of each group had no history of CVD. The results suggested that CVD events were increased with aspirin use and that there was no difference in mortality or bleeding events. The surprising results of this study may relate to the limitations of observational studies.

Current guidance in relation to aspirin and CVD primary prevention in CKD does not specify either use or avoidance $[7,8,13]$. In DM, regardless of CKD status, the current consensus is in favour of the use of aspirin in patients with DM and more than $10 \% 10$ year risk of a CV event if not at increased risk for bleeding [5]. Increased risk of bleeding was defined as "previous gastrointestinal bleeding or peptic ulcer disease or concurrent use of other medications that increase bleeding risk'. More recently, an updated meta-analysis [27] has concluded that 'emerging data do not clearly support guidelines' in relation to aspirin for CV event primary prevention in DM. Similarly, the current meta-analysis suggests that no firm recommendation for the benefit of aspirin can be given for individuals with CKD but additional caution should be taken in relation to bleeding related adverse event. Due to these limitations of the included trials, further randomised controlled trials are required in this area. Currently, there is only one registered trial of this specific subject [9]. 
In summary, the role of aspirin for the primary prevention of atherosclerotic disease in CKD is poorly studied. Overall, these 3 trials suggest that there is no clear benefit of aspirin but major bleeding events are increased. Therefore, the universal use of aspirin for the primary prevention of CVD in CKD can not be routinely recommended and further high quality, CKD specific randomised control trials are required. 


\section{Acknowledgements}

We would like to thank Dr Takeshi Morimoto and his team for providing additional data in relation to the JPAD study. We would also like to thank Dr Ben Storey, Dr William Herrington and Professor Colin Baigent for providing additional data in relation to the UK-HARP-I study.

Dr Rupert W Major was a National Institute for Health Research (NIHR) funded Academic Clinical Fellow at the time of some this research taking place. He is currently a Kidney Research UK funded Academic Clinical Fellow. The views expressed are those of the author(s) and not necessarily those of the NHS, the NIHR, the Department of Health or Kidney Research UK. 


\section{References}

1. Stevens $P, O^{\prime} D o n o g h u e ~ D$, de Lusignan $S$ et al. Chronic kidney disease management in the United Kingdom: NEOERICA project results. Kidney Int. 2007;72(1):92-99.

2. Go A, Chertow G, Fan D, McCulloch C, Hsu C. Chronic Kidney Disease and the Risks of Death, Cardiovascular Events, and Hospitalization. N Engl J Med. 2004;351(13):1296-1305.

3. Berger JS, Brown DL, Becker RC. Low-dose aspirin in patients with stable cardiovascular disease: a meta-analysis. Am J Med. 2008;121(1),43-49.

4. The National Institute for Health and Care Excellence (2009). Type 2 diabetes: The management of type 2 diabetes. Retrieved from http://www.nice.org.uk/guidance/cg87

5. Pignone M, Alberts MJ, Colwell JA et al. Aspirin for Primary Prevention of Cardiovascular Events in People With Diabetes: A Position Statement of the American Diabetes Association, a Scientific Statement of the American Heart Association, and an Expert Consensus Document of the American College of Cardiology Foundation. Circulation. 2010;121:2694-2701.

6. Baigent C, Blackwell L, Collins R et al. Aspirin in the primary and secondary prevention of vascular disease: collaborative meta-analysis of individual participant data from randomised trials. Lancet. 2009;373(9678):1849-60.

7. The National Institute for Health and Care Excellence (2014). Chronic kidney disease: early identification and management of chronic kidney disease in adults in primary and secondary care. Retrieved from http://www.nice.org.uk/guidance/cg182

8. Kidney Disease Improving Global Outcomes (KDIGO) CKD Work Group: KDIGO 2012 clinical practice guideline for the evaluation and management of chronic kidney disease. Kidney Int Suppl. 3: 1-150, 2013

9. Identifier NCT01709994. National Institute of Health: ClinicalTrials.gov. Available at http://clinicaltrials.gov. Accessed October 13, 2015.

10. Jardine MJ, Ninomiya T, Perkovic $V$ et al. Aspirin is beneficial in hypertensive patients with chronic kidney disease: a post-hoc subgroup analysis of a randomized controlled trial. J Am Coll Cardiol. 2010;56(12):956-965. 
11. Kim A, Lim H, Ro H et al. Low-Dose Aspirin for Prevention of Cardiovascular Disease in Patients with Chronic Kidney Disease. PLoS One. 2014;9(8):e104179.

12. Palmer SC, Di Micco L, Razavian M et al. Effects of antiplatelet therapy on mortality and cardiovascular and bleeding outcomes in persons with chronic kidney disease: a systematic review and meta-analysis. Ann Intern Med. 2012;156(6):445-459.

13. Bilo H, Coentrão L, Couchoud C et al. Clinical Practice Guideline on management of patients with diabetes and chronic kidney disease stage $3 \mathrm{~b}$ or higher (eGFR< 45 mL/min). Nephrol Dial Transplant. 2015;30(suppl 2):ii1ii142.

14. Crd.york.ac.uk. PROSPERO - International prospective register of systematic reviews [Internet]. 2015 [cited 13 October 2015]. Available from: http://www.crd.york.ac.uk/PROSPERO/

15. Higgins JPT, Green S (editors): Cochrane Handbook for Systematic Reviews of Interventions, version 5.1.0, 2011. Available at http://www.cochranehandbook.org. Accessed November 12, 2015

16. Baigent C, Landray M, Leaper $C$ et al. First United Kingdom Heart and Renal Protection (UK-HARP-I) study: biochemical efficacy and safety of simvastatin and safety of low-dose aspirin in chronic kidney disease. Am J Kidney Dis. 2005;45(3):473-484.

17. Saito $\mathrm{Y}$, Morimoto $\mathrm{T}$, Ogawa $\mathrm{H}$ et al. Low-Dose Aspirin Therapy in Patients With Type 2 Diabetes and Reduced Glomerular Filtration Rate Subanalysis from the JPAD trial. Diabetes care. 2011;34(2):280-285.

18. Levey AS, Bosch JP, Lewis JB, Greene T, Rogers N, Roth D; Modification of Diet in Renal Disease Study Group: A more accurate method to estimate glomerular filtration rate from serum creatinine: A new prediction equation. Ann Intern Med 130: 461-470, 1999

19. Matsuo S, Imai E, Horio M, et al.; Collaborators developing the Japanese equation for estimated GFR. Revised equations for estimated GFR from serum creatinine in Japan. Am J Kidney Dis 2009;53:982-992

20. Weigert AL, Schafer Al. Uremic bleeding: pathogenesis and therapy. Am J Med Sci. 1998;316(2):94-104. 
21. Sutcliffe $P$, Connock $M$, Gurung $T$ et al. Aspirin for prophylactic use in the primary prevention of cardiovascular disease and cancer: a systematic review and overview of reviews. Health Technology Assessment. 2013;17(43):1-253

22. Tangri N, Kitsios GD, Inker LA et al. Risk prediction models for patients with chronic kidney disease: a systematic review. Ann Int Med. 2013;158(8):596603.

23. Weiner $\mathrm{DE}$, Tighiouart $\mathrm{H}$, Elsayed $\mathrm{EF}$ et al. The Framingham predictive instrument in chronic kidney disease. J Am Coll Cardiol. 2007;50(3):217-224.

24. Tonelli M, Muntner P, Lloyd A, Manns BJ, Klarenbach S, Pannu N, James MT, Hemmelgarn BR, Alberta Kidney Disease Network. Risk of coronary events in people with chronic kidney disease compared with those with diabetes: a population-level cohort study. The Lancet. 2012 Sep 7;380(9844):807-14.

25. Fox CS, Matsushita K, Woodward M, Bilo HJ, Chalmers J, Heerspink HJ, Lee BJ, Perkins RM, Rossing P, Sairenchi T, Tonelli M. Associations of kidney disease measures with mortality and end-stage renal disease in individuals with and without diabetes: a meta-analysis. The Lancet. $2012 \mathrm{Nov}$ 16;380(9854):1662-73.

26. Mahmoodi BK, Matsushita K, Woodward M, Blankestijn PJ, Cirillo M, Ohkubo T, Rossing P, Sarnak MJ, Stengel B, Yamagishi K, Yamashita K. Associations of kidney disease measures with mortality and end-stage renal disease in individuals with and without hypertension: a meta-analysis. The Lancet. 2012 Nov 16;380(9854):1649-61.

27. Kunutsor SK, Seidu S, Khunti K. Aspirin for primary prevention of cardiovascular and all-cause mortality events in diabetes: updated metaanalysis of randomized controlled trials. Diabetic Med. 2016, accepted for publication. Accessed $19^{\text {th }}$ May 2016.

http://onlinelibrary.wiley.com/doi/10.1111/dme.13133/abstract 


\section{Table and Figures Legend}

\section{Tables}

1. Summary details of included studies. Study acronyms - HARP - 'First United Kingdom Heart and Renal Protection', HOT - 'Hypertension Optimal Treatment', JPAD - 'The Japanese Primary Prevention of Atherosclerosis With Aspirin for Diabetes'. Data from HARP for the percentage of individuals with hypertension in the CKD subgroups was not available, in the whole HARP cohort mean systolic blood pressure was $144 \mathrm{mmHg}$ (SD 20mm Hg) in the aspirin group and $142 \mathrm{mmHg}$ (SD $21 \mathrm{mmHg}$ ) in the placebo group. Mean diastolic blood pressure was $83 \mathrm{mmHg}$ (SD $12 \mathrm{mmHg}$ ) in the aspirin group and $84 \mathrm{mmHg}$ (SD $11 \mathrm{mmHg}$ ) in the placebo group.

2. Summary results of random effects models, heterogeneity $\left(I^{2}\right)$, ARR per 100 person-years and NNT over 5 years to prevent one event.

\section{Figures}

1. Flowchart showing the number of papers identified, screened and included in the meta-analysis.

2. Forest plot of risk ratios for CVD events using a random effects model and M$\mathrm{H}$ method.

3. Forest plot of risk ratios for major bleeding events using a random effects model and $\mathrm{M}-\mathrm{H}$ method 


\section{Conflicts of Interest}

All authors: No conflicts of interest to declare.

Dr Major is currently a Kidney Research UK funded Academic Clinical Fellow.

This study was not directly funded and the authors have no relevant financial support disclosures to make. All authors have reviewed and agreed on the content of this manuscript. The results presented in this paper have not been published previously in whole or part, except in abstract form. 


\section{Appendix 1 - OVID Medline Search Strategy}

1 ckd.tw.

2 kidney*.tw.

3 nephro\$.tw.

4 exp Renal Insufficiency, Chronic/

5 renal.tw.

61 or 2 or 3 or 4 or 5

7 exp Clinical Trial/

8 exp Randomized Controlled Trials as Topic/

9 placebo\$.tw.

10 random $\$ . t w$.

11 trial\$.tw.

12 ('single blind"' or 'single-blind").tw.

13 (double blind* or double-blind ${ }^{*}$ ).tw.

14 'comparative stud*'.tw.

15 exp Evaluation Studies/

16 'evaluation stud*'.tw.

17 'prospective stud*'.tw.

18 'cross-over stud'.tw.

19 'follow-up stud'.tw.

207 or 8 or 9 or 10 or 11 or 12 or 13 or 14 or 15 or 16 or 17 or 18 or 19

21 aspirin.tw.

22 exp Aspirin/

23 \$salicyl\$.tw.

24 asa.tw.

25 anti-platelet.tw.

26 antiplatelet.tw.

2721 or 22 or 23 or 24 or 25 or 26

$28 \quad 6$ and 20 and 27 
Appendix 2 - Risk of Bias Assessment

\begin{tabular}{|c|c|c|c|c|c|c|c|c|c|c|}
\hline \multirow[t]{2}{*}{ Study } & \multirow{2}{*}{$\begin{array}{l}\text { Is it possible to make a } \\
\text { full assessment of the } \\
\text { methods? }\end{array}$} & \multicolumn{2}{|c|}{ Selection Bias } & \multirow[t]{2}{*}{$\begin{array}{c}\text { Performance } \\
\text { bias }\end{array}$} & \multirow[t]{2}{*}{$\begin{array}{c}\text { Detection } \\
\text { bias }\end{array}$} & \multirow[t]{2}{*}{$\begin{array}{c}\text { Attrition } \\
\text { bias }\end{array}$} & \multirow[t]{2}{*}{$\begin{array}{c}\text { Reporting } \\
\text { bias }\end{array}$} & \multirow[t]{2}{*}{$\begin{array}{l}\text { Other } \\
\text { bias }\end{array}$} & \multirow[t]{2}{*}{$\begin{array}{c}\text { eGFR } \\
\text { /proteinuria }\end{array}$} & \multirow[t]{2}{*}{ Overall } \\
\hline & & $\begin{array}{l}\text { Random } \\
\text { sequence } \\
\text { generation }\end{array}$ & $\begin{array}{l}\text { Allocation } \\
\text { Concealmet }\end{array}$ & & & & & & & \\
\hline JPAD & Yes & Low & High & High & Low & Low & Medium & Low & Medium & High \\
\hline HOT & Yes & Low & Low & Low & Low & Low & Low & Medium & Medium & Medium \\
\hline HARP & Yes & Low & Medium & Low & Medium & Low & Low & Medium & Medium & Medium \\
\hline
\end{tabular}

